\title{
AN ATTEMPT AT GROUPING OF THE GENUS PSEUDOMONAS
}

\author{
HIROSHI IIZUKA and KAZUO KOMAGATA ${ }^{1}$ \\ Institute of Applied Microbiology, University of Tokyo, Tokyo \\ Received October 23, 1962
}

The generic name of Pseudomonas was given by Migula (1) in 1894 to the group of bacteria which were Gram negative rods possessing polar flagella. Ps. aeruginosa was chosen as the type species. The beautiful greenish yellow fluorescent pigments are produced by some species. Pseudomonads are widely distributed in nature, and are isolated from many sources, such as river water (2,3), sewage, beer (4), maple sap (5), dairy products $(6)$, cereals $(7)$, petroleum (8), natural gas brine (8), etc.

The generic concept of Pseudomonas has been mainly based upon cell morphology, flagellation, and Gram stain, and it includes the largest number of species in Pseudomonadaceae. Migula (9) divided this genus into five groups based upon the characteristics of pigmentation. In both BERGEY's (10) and KRASSILNIKov's manuals(11), the production of pigments is used for the differential key of this genus. However, the pigmentation was chosen merely for the sake of convenience, and its taxonomical value was not critically evaluated. Although the significance of some taxonomical characteristics of this genus has been reported by several investigators $(12-16)$, the number of strains and species studied was too limited to cover the whole generic group. In the present paper, the authors describe the results of comparative and systematic studies on the physiological, biochemical and ecological features of Pseudomonas strains, which led to the conclusion that taxonomically the genus should be divided into three groups on the basis of the characteristics of pigmentation. Details on the systematic of this genus will be reported elsewhere.

\section{MATERIALS AND METHODS}

Microorganisms. Pseudomonads tested were both those freshly isolated from cereals, petroleum, natural gas brine, etc. by the authors, and those obtained from the type culture collections of several institutions including the Institute of Applied Microbiology, University of Tokyo. Those comprised 202 strains belonging to 28 species. In Table 1 are shown the number of strains and species tested and the sources of their isolation. Marine and plant pathogenic pseudomonads were excluded from this study.

1) Present address: Central Research Laboratory, Ajinomoto Co., Inc., 2964, Suzuki-cho, Kawasaki, Japan. 
Table 1. Species of Pseudomonas and sources of isolation

\begin{tabular}{|c|c|c|c|c|c|c|c|}
\hline & $\frac{\mathscr{0}}{\stackrel{\Xi}{ \pm}}$ & 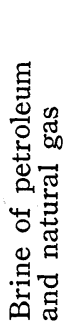 & 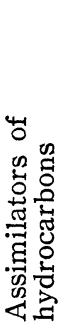 & 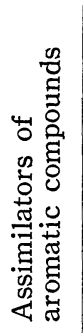 & 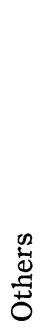 & 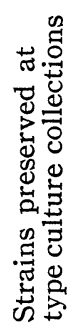 & 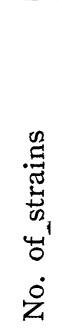 \\
\hline $\begin{array}{l}\text { Fluorescent group } \\
\text { Ps. aeruginosa } \\
\text { Ps. azotoformans } \\
\text { Ps. chlororaphis } \\
\text { Ps. pavonacea } \\
\text { Ps. schuylkilliensis } \\
\text { Ps. aureofaciens } \\
\text { Ps. cinnamona } \\
\text { Ps. straminea } \\
\text { Ps. nitroreducens } \\
\text { Ps. ovalis } \\
\text { Ps. rugosa } \\
\text { Ps. fulva }\end{array}$ & $\begin{array}{l}1 \\
6 \\
7 \\
3 \\
1 \\
\\
3 \\
3 \\
6\end{array}$ & $\begin{array}{l}7 \\
4 \\
4\end{array}$ & 1 & 6 & $\begin{array}{l}11 \\
12\end{array}$ & $\begin{array}{r}17 \\
2\end{array}$ & $\begin{array}{r}28 \\
20 \\
2 \\
6 \\
21 \\
1 \\
3 \\
1 \\
6 \\
27 \\
3 \\
6\end{array}$ \\
\hline $\begin{array}{l}\text { Achromogenic group } \\
\text { Ps. putrefaciens } \\
\text { Ps. alcaligenes } \\
\text { Ps. stutzeri } \\
\text { Ps. rathonis } \\
\text { Ps. denitrificans } \\
\text { Ps. desmolytica } \\
\text { Ps. dacunhae } \\
\text { Ps. riboflavina } \\
\text { Ps. iners } \\
\text { Ps. diminuta }\end{array}$ & 30 & $\begin{array}{l}17 \\
2 \\
\\
5 \\
6\end{array}$ & $\begin{array}{l}4 \\
6\end{array}$ & $\begin{array}{l}3 \\
3\end{array}$ & $\begin{array}{l}1 \\
1\end{array}$ & $\begin{array}{r}21 \\
1\end{array}$ & $\begin{array}{r}124 \\
4 \\
5 \\
6 \\
6 \\
4 \\
11 \\
3 \\
1 \\
3 \\
1\end{array}$ \\
\hline $\begin{array}{l}\text { Chromogenic group } \\
\text { Ps. perlurida } \\
\text { Ps. trifolii } \\
\text { Ps. cerealis } \\
\text { Ps. melanogenum } \\
\text { Ps. lacunogenes } \\
\text { Ps. ochracea }\end{array}$ & $\begin{array}{r}1 \\
7 \\
3 \\
4 \\
4 \\
13 \\
2\end{array}$ & 16 & 15 & 6 & 3 & 1 & $\begin{array}{r}44 \\
\\
7 \\
4 \\
4 \\
4 \\
13 \\
3\end{array}$ \\
\hline & 33 & & & & & 1 & 34 \\
\hline Total & 64 & 33 & 16 & 13 & 51 & 25 & 202 \\
\hline
\end{tabular}


Experimental methods used were mainly those described in the "Manual of Microbiological Methods"(17). All the tests except liquefaction of gelatin were carried out at $30^{\circ}$.

Morphological characteristics. Cell form, motility, size, and Gram stain were observed on the cells cultured on nutrient agar slants for 18 to $24 \mathrm{hr}$. The capsule formation was examined after 4 to 5 days' incubation. The irregular form was observed after 7 to 10 days' incubation. The flagellation was confirmed by the staining method of Nishizawa and Sugawara (18) and by electron microscopy.

Cultural characteristics. The growth, surface structure, pigmentation, etc. of nutrient agar and glutamate agar plate cultures were observed after 5 to 7 days' incubation. On nutrient agar and glutamate agar slants, the same characteristics were noted after 3 to 5 days' incubation. Formation of pellicle, pigments, turbidity, etc. were observed in liquid cultures. Cultures on nutrient gelatin were incubated at $20^{\circ}$ and $30^{\circ}$ for a month. For the milk test B.C.P was used as $\mathrm{pH}$ indicator.

Biochemical and physiological characteristics.

a) Production of pigments

Water-soluble pigments were produced in the cultures in glutamate broth and the other synthetic media but not in those in nutrient broth. The following medium, composed of $10 \mathrm{~g}$ glycerol, $2.5 \mathrm{~g}$ ammonium lactate, $5.0 \mathrm{~g}$ sodium glutamate, $1.0 \mathrm{~g} \mathrm{~K}_{2} \mathrm{HPO}_{4}, 0.5 \mathrm{~g} \mathrm{MgSO}_{4} \cdot 7 \mathrm{H}_{2} \mathrm{O}, 0.1 \mathrm{~g} \mathrm{KCl}$, and $1,000 \mathrm{ml}$ of dist. water $(\mathrm{pH} \mathrm{7.2)}$, was used for the detection of formation of watersoluble pigments. The production of non-water-soluble pigments was tested on slant or plate cultures of nutrient agar and glutamate agar.

b) Reduction of nitrate

Nutrient broth with $0.2 \%$ of potassium nitrate, and succinate-nitrate broth (19) were used for the tests of reduction of nitrate. Nitrite was detected by applying $\alpha$-naphtylamine and sulfanilic acid after 1,3 , and 5 days' incubation.

c) Nitrate respiration

Anaerobic growth occurring with the performance of nitrate respiration was examined by the following procedure. The cells grown on nutrient agar slant were inoculated in a nutrient broth containing $1 \%$ of potassium nitrate, and the cultures was immediately sealed with sterilized liquid paraffine. For controls, unsealed cultures in nutrient broth with or without potassium nitrate and sealed cultures in nutrient broth without potassium nitrate were also run. After 1 to 2 days' incubation, growth, turbidity, and bubbling of gas were observed.

d) Production of indole

Indole was detected by using Kovac's reagent after 1, 3, and 5 days' incubation in 1\% tryptone (Difco) water.

e) Production of hydrogen sulfide 
Nutrient broth containing $0.05 \%$ cysteine was used for the test of production of hydrogen sulfide. Hydrogen sulfide was detected by using the lead acetate paper strip.

f) Hydrolysis of starch

Streak cultures on nutrient agar plates containing $0.2 \%$ of soluble starch were treated with iodine solution after 1, 3, and 5 days' incubation.

g) Catalase

Young cells grown on nutrient agar slants for 18 to $24 \mathrm{hr}$ were dipped in $3 \%$ aqueous solution of hydrogen peroxide, and production of bubbles was examined.

h) Relation to temperature

Growth at temperatures of $5^{\circ}, 10^{\circ}, 25^{\circ}, 30^{\circ}, 37^{\circ}$, and $42^{\circ}$ were compared using nutrient broth as culture medium.

\section{RESULTS}

The experimental results are summarized in Tables 2 and 3.

\section{Morphological characteristics}

The strains tested were all motile except two and all Gram negatve. In no case was the staining positive, variable or irregular. Cells were invariably strainght rods and not curved. They occurred singly or in pairs, but not in long chains. In older cultures (about 7 to 10 days' incubation) there appeared cells bulged at terminal, and cells over 40 microns in length on rare occasions. All the motile strains showed polar flagellation, with no indication of the generation of lateral flagella. The number of flagella varied with species and strains. Two non-motile varities found in the group produced water-soluble greenish yellow fluorescent pigments. All the strains tested were non-acid fast, and almost all of them formed no capsule: No particular relation was recognized between the morphological characteristics and the production of pigments.

\section{Cultural characteristics}

The cultural characteristics of Pseudomonas are not so distinct as those of other bacteria or of yeasts and molds. Colonies on nutrient agar are mostly circular, smooth or rough with textures that are in most cases butyrous and rarely membranous. Pigmentation and surface structure of colonies are more distinctive in the colonies on glutamate agar than in those on nutrient agar. The slant cultures showed characteristics similar to those of agar colonies. On glutamate agar colonies of Ps. lacunogenes and Ps. stutzeri had markedly wrinkled surface and colonies of Ps. perlurida and Ps. trifolii showed metalic sheen. These characteristics of colonies appeared less marked when the organisms were grown on nutrient agar. Some strains formed pellicle but some others not. About half of the species tested liquefied gelatin. Ps. straminea, Ps. lacunogenes, and 


\begin{tabular}{|c|c|c|c|}
\hline 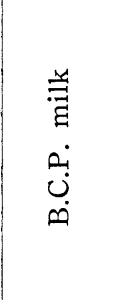 & 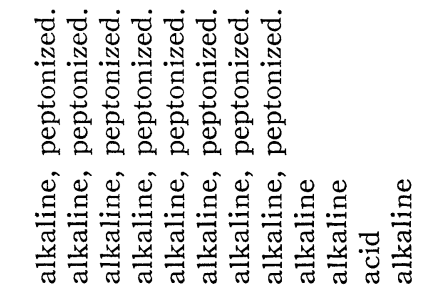 & 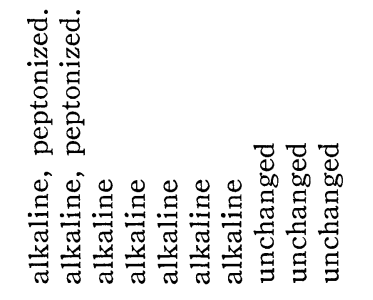 & 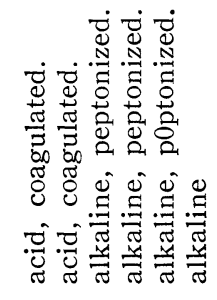 \\
\hline 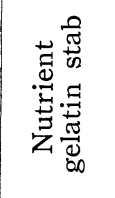 & 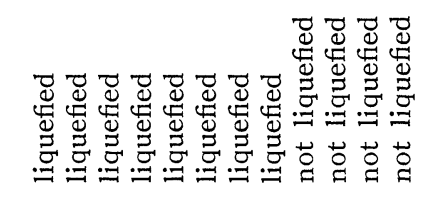 & 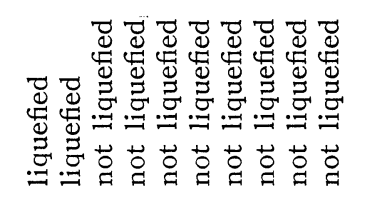 & 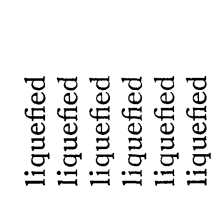 \\
\hline 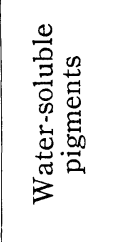 & 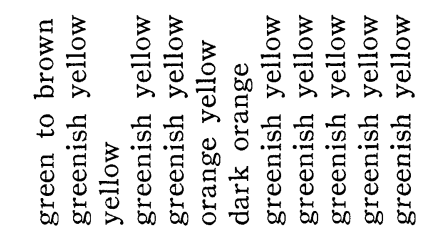 & 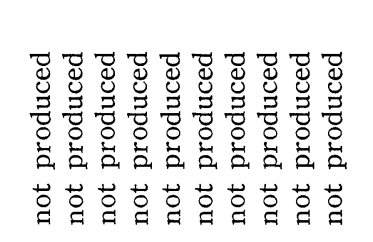 & 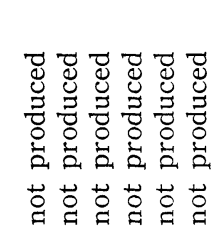 \\
\hline 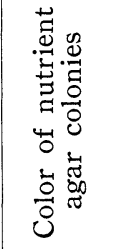 & 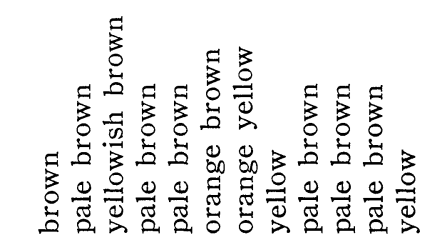 & 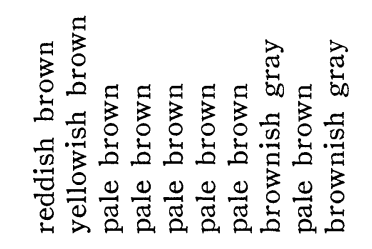 & 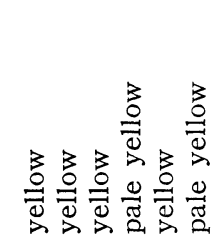 \\
\hline $\begin{array}{l}\text { surexps } \\
\text { go }{ }^{\circ} \mathrm{ON}\end{array}$ & 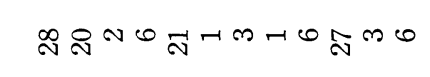 & $\forall 1500 \forall=10-1$ & 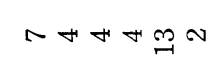 \\
\hline & 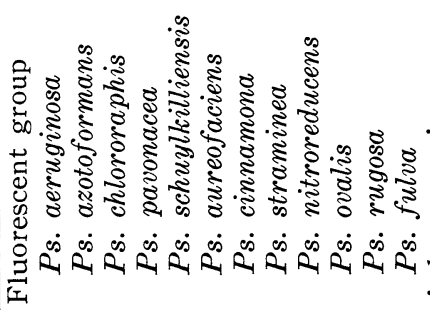 & 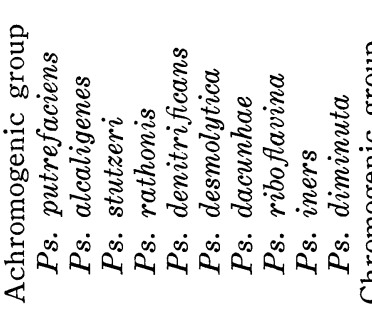 & 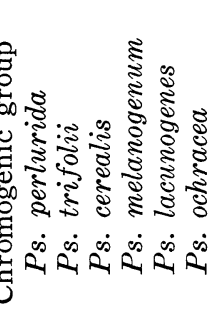 \\
\hline
\end{tabular}


Table 3. Physiological and biochemical characteristics

\begin{tabular}{|c|c|c|c|c|c|c|c|c|c|c|}
\hline & \multirow{2}{*}{ 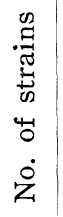 } & \multirow{2}{*}{ 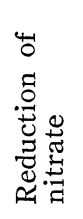 } & \multirow{2}{*}{ 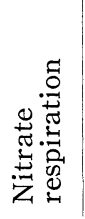 } & \multirow[b]{2}{*}{ 诘 } & \multirow[b]{2}{*}{$\underset{⿱ 乛}{\stackrel{0}{0}}$} & \multirow{2}{*}{ 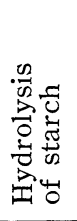 } & \multicolumn{3}{|c|}{ Growth at } & \multirow[b]{2}{*}{ 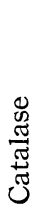 } \\
\hline & & & & & & & $30^{\circ}$ & $37^{\circ}$ & $42^{\circ}$ & \\
\hline \multicolumn{11}{|l|}{ Fluorescent group } \\
\hline Ps. aeruginosa & 28 & + & + & - & - & - & + & + & + & + \\
\hline Ps. azotofromans & 20 & + & + & - & - & - & + & - & - & + \\
\hline Ps. chlororaphis & 2 & + & + & - & - & - & + & \pm & - & + \\
\hline Ps. pavonacea & 6 & - & - & - & - & - & + & + & - & + \\
\hline Ps. schuylkilliensis & 21 & - & - & - & - & - & + & \pm & - & + \\
\hline Ps. aureofaciens & 1 & + & - & - & - & - & + & \pm & - & + \\
\hline Ps. cinnamona & 3 & - & - & + & - & - & + & \pm & - & + \\
\hline Ps. straminea & 1 & - & - & + & - & - & + & + & - & + \\
\hline Ps. nitroreducens & 6 & + & + & - & - & - & + & \pm & - & + \\
\hline Ps. ovalis & 27 & - & - & - & - & - & + & + & - & + \\
\hline Ps. rugosa & 3 & - & - & - & - & - & + & - & - & + \\
\hline Ps. fulva & 6 & - & - & \pm & - & - & + & + & - & + \\
\hline \multicolumn{11}{|l|}{ Achromogenic group } \\
\hline Ps. putrefaciens & 4 & + & - & $++t$ & - & + & + & - & - & + \\
\hline Ps. alcaligenes & 5 & + & - & $++t$ & - & - & + & + & - & + \\
\hline Ps. stutzeri & 6 & + & + & - & - & + & + & + & - & + \\
\hline Ps. rathonis & 6 & + & + & - & - & + & + & + & - & + \\
\hline Ps. denitrificans & 4 & + & + & ++ & - & - & + & + & - & + \\
\hline Ps. desmolytica & 11 & + & - & + & - & - & + & + & - & + \\
\hline Ps. dacunhae & 3 & - & - & + & - & - & + & + & - & + \\
\hline Ps. riboflavina & 1 & - & - & + & - & - & + & - & - & + \\
\hline Ps. iners & 3 & - & - & - & - & - & + & - & - & + \\
\hline Ps. diminuta & 1 & - & - & - & - & - & + & + & - & + \\
\hline \multicolumn{11}{|l|}{ Chromogenic group } \\
\hline Ps. perlurida & 7 & - & - & + & + & - & + & + & - & + \\
\hline Ps. trifolii & 4 & + & - & + & - & - & + & - & - & + \\
\hline Ps. cerealis & 4 & - & - & + & - & + & + & + & + & + \\
\hline Ps. melanogenum & 4 & + & - & ++ & - & - & + & - & - & + \\
\hline Ps. lacunogenes & 13 & - & - & + & - & - & + & + & \pm & + \\
\hline Ps. ochracea & 2 & - & - & + & - & - & + & + & \pm & + \\
\hline
\end{tabular}

Ps. ochracea scarecely liquefied gelatin at $20^{\circ}$, but rapidly at $30^{\circ}$. The reaction to milk was generally alkaline, and almost half of the species peptonized casein. Prior to peptonization, some strains coagulated milk 
giving neutral or alkaline reaction, a rennet-like coagulation. Ps. perlurida and Ps. trifolii compactly coagulated milk causing acidification, acid coagulation.

\section{Biochemical and physiological characteristics}

a) Production of pigments

According to the characteristics of pigment formation, the strains tested were divided into the following three groups: (1) those producing water-soluble greenish-yellow-fluorescent pigments, (2) those producing neither water-soluble nor non-water-soluble pigments, and (3) those producing non-water-soluble yellow pigments. The representative of Group (1) is $P s$. aeruginosa which produces as major pigment the well- known compound pyocyanine. Members of the same group are: Ps. azotoformans, Ps. chlororaphis, Ps. pavonacea, Ps. schuylkilliensis, Ps. aureofaciens, Ps. cinnamona, Ps. straminea, Ps. nitroreducens, Ps. ovalis, Ps. rugosa, and Ps. fulva. In general characteristics of this group, the following species may also be included in this group, although they produce, besides water-soluble pigments, some non-water-soluble yellow pigments: Ps. cinnamona, Ps. straminea, and Ps. fulva. Group (2) comprises Ps. putrefaciens, Ps. alcaligenes, Ps. stutzeri, Ps. rathonis, Ps. denitrificans, Ps. desmolytica, Ps. dacunhae, Ps. riboflavina, Ps. iners, and Ps. diminuta, and Group (3): Ps. perlurida, Ps. trifolii. Ps. cerealis, Ps. melanogenum, Ps. lacunogenes, and Ps. ochracea. Among these, Ps. melanogeneum had a specific character of changing the color of nutrient agar containing tyrosine dark brown, which seems to be due to the formation of melanine.

b) Reduction of nitrate

In nitrate broth, some species reduced nitrate to nitrite. Almost all the strains which grew in succinate-nitrate broth accumulated nitrite in the presence of nitrate. Reduction of nitrate accompanied by production of gaseous nitrogenous compounds was observed with Ps. aeruginosa, Ps. azotoformans, Ps. nitroreducens, Ps. stutzeri, Ps. rathonis, Ps. denitrificans, etc. Some of the strain tested, when grown for 5 to 7 days in nitrate broth, produced only a trace of nitrite (less $3 \gamma / \mathrm{ml}$ ), while they produced a large amount of nitrite in the ealy stage of growth in succinate-nitrate broth, indicating that their mode of assimilating and reducing nitrate is different according to the composition of the medium applied. In our description of experimental results, the production of nitrite in amount of more than $5 \mathrm{r} / \mathrm{ml}$ in the early culture stage was recorded as being positive in regard to the test of nitrate reduction.

c) Nitrate respiration

A considerable number of species of Pseudomonas were found to be capable of growing anaerobically by performing nitrate respiration. These were, when classified according to their characteristics of pigment formation: 
Ps. aeruginosa, Ps. azotoformans, Ps. nitroreducens, and Ps. chlororaphis of Group (1); Ps. stutzeri, Ps. rathonis, and Ps. denitirificans of Group (2). Noteworthy was the fact that there was no species possessing the ability of nitrate respiration in Group (3). Almost all the strains which grew anaerobically by performing nitrate respiration showed a property of producing gaseous nitrogenous compounds from nitrate.

d) Production of indole

Indole was produced only by Ps. perlurida which belongs to Group (3).

e) Production of hydrogen sulfide

Nearly all the strains belonging to Groups (2) and (3) produced hydrogen sulfide abundantly, while those belonging to Group (1) scarecely produced it.

f) Hydrolysis of starch

Starch was hydrolyzed by Ps. stutzeri, and Ps. rathonis of Group (2) and Ps. cerealis of Group (3). The strains beloning to Group (1) were all incapable of hydrolyzing starch.

g) Catalase

All the strains belonging to the three groups contained catalase, although some strains belonging to Group (2), namely Ps. putrefacines, Ps. alcaligenes, and Ps. riboflavina showed weaker catalase activity compared with other species.

h) Relation to temperature

Generally, the optimum temperature for the growth ranged from $25^{\circ}$ to 30. Several strains of Group (1) grew well at $5^{\circ}$ and $10^{\circ}$. Ps. aeruginosa grew well at $42^{\circ}$.

\section{DISCUSSION}

According to the characteristics of pigmentation the strains belonging to the genus Pseudomonas were divided into three groups: (1) Those producing water-soluble greenish yellow fluorescent pigments, sometimes accompanied by non-water soluble pigments; (2) those producing neither water-soluble nor non-water-soluble pigments; and (3) those producing only non-water-soluble yellow pigments. Compared with the strains belonging to Groups (2) and (3), those beloning to Group (1) are biochemically more active, being, in most cases, capable of growing on simple synthetic media. However, they do not produce hydrogen sulfide nor hydrolyze starch. Nearly all the strains belonging to Group (2) produce hydrogen sulfide. Among the strains of this group, Ps. riboflavina Ps. alcaligenes, $P s$. iners, and Ps. diminuta do not grow on simple synthetic media. The third group is characterized by their lack of capacity for growing anaerobically by performing nitrate respiration. Ps. lacunogenes of this group forms membranous colonies on nutrient agar and glutamate agar, which was never observed with other strains tested.

It has already been reported by the present authors that for various strains of Pseudomonas we can find certain parallel relations between the 
chracteristics of pigmentation and other biochemical properties, such as accumulation of amino acids (20), oxidation of steroid (21), and nutritional requirements (19). Interesting relations were also found in ecological characteristics on the organisms in question: namely, as shown in Table 1, the species of the first group were mainly those isolated from soil, sewage, water, etc, the species of the second group were chiefly those found in oil-brine (8), and the organisms belonging to the third group were those specifically found in cereal grains ( 7$)$.

Based on these facts the authors propose the grouping of the genus Pseudomonas according to the characteristics of pigmentation, calling the first group Fluorescent group, the second group Achromogenic group, and the third group Chromogenic group. The following is the taxonomic description of three groups.

1. Fluorescent group

Produce water-soluble yellowish green to orange pigments, usually fluorescent. Some species produce non-water-soluble pigments besides water-soluble ones. Good growth on glutamate agar. A number of species reduce nitrate to nitrite in succinate-nitrate broth. Aerobe. Some species grow anaerobically by performing nitrate respiration. Hydrogen sulfide is hardly produced. Starch is not hydrolyzed. Widely distributed in water, sewage, soil, etc. Ps. aeruginosa is the type species.

2. Achromogenic group

Do not produce either water-soluble or non-water-soluble pigments. Some species grow on glutamate agar. Reduction and assimilation of nitrate vary with species. Some species grow anaerobically by performing nitrate respiration. Hydrogen sulfide is produced. Indole is not produced. The nutritional requirements are more complex than those of the fluorescent group. Widely distributed in water, sewage, especially in oil-brine. Ps. putrefaciens is the type species.

3. Chromogenic group

Produce non-water-soluble pigments. Some species grow on glutamate agar. Reduction and assimilation of nitrate vary with species. Aerobe. No strains was found to grow anaerobically by performing nitrate respiration. Hydrogen sulfide is produced. Starch is hydrolyzed by one species. Indole is produced by Ps. perlurida. The reaction to milk is usually alkaline. Ps. perlurida and Ps. trifolii coagulated milk. The nutritional requirements are more complex than those of the fluorescent group. Widely distributed in cereal grains. Ps. lacunogenes is the type species.

\section{SUMMARY}

Taxonomical studies on the genus Pseudomonas were carried out with 28 species and 202 strains, including those obtained from several type culture collections as well as those isolated from various sources by the 
authors. The cultural, biochemical, physiological and ecological properties of these organisms were found to be more or less closely correlated to the characteristics of pigmentation. In respect to the pigmentation characteristics, distinction was made of three groups which were named: Fluorescent group, Achromogenic group and Chromogenic group.

The authors wish to thank Mr. C. Uchino and Mr. C. Sugiyama for their technical assistance.

\section{REFERENCES}

(1) W. Migula: Abt. Bacteriol. Inst. Karlsruhe, 1, 237 (1894); cited from W. Migula: System der Bakterien, II 875 (1900) and Judicial Commission Opinion No. 5: Internatl. Bull. Bact. Nomen. Taxon. 2, 121 (1952).

(2) J. H. Wright: Memo. Natl. Acad. Sci., 1, 422 (1895).

(3) E. O. JoRDaNn: J. Hyg., 3, 1 (1903).

(4) F. Fuhrman: Z. Bakt., II 16, 309 (1906).

(5) H. A. Edson and C. W. Carpenter: Vermont Agr. Expt. Sta. Bull., 167, 521 (1912) cited from reference No. 6.

(6) W. A. Seleen and C. N. Stark: J. Bacteriol., 46, 491 (1943).

(7) H. Irzuka: J. Gen. Appl. Microbiol., 3, 146 (1957), 4, 108 (1958).

(8) H. Iizuka and K. Komagata: Soil and Microbe (in Japanese) No. 2, 32 (1961).

(9) W. Migula: System der Bakterien II 875 (1900). Gustav Fischer.

(10) R. S. BREed et al.: Bergey's Manual of Determinative Bacteriology 7 th ed. (1957). Williams and Wilkins.

(11) N. A. Krassilnikov: Diagnostik der Bakterien und Actinomyceten (1959). Gustav Fischer.

(12) S. RuzicKa: Arck. Hyg., 34, 149 (1899).

(13) F. TANNER: J. Bacteriol., 3, 63 (1918).

(14) W. C. Haynes: J. Gen. Microbiol., 5, 939 (1951).

(15) W. L. GABY and E. FREE: J. Bacteriol., 76, 442 (1958).

(16) M. E. RHodes: J. Gen. Microbiol., 21, 221 (1959).

(16) M. J. Pelczar: Manual of Microbiological Methods (1957) McGraw-Hill.

(18) Denken-Gakuyu Kai: Saikingaku Zitsushu Teiyo (in Japanese) (1955) Maruzen.

(19) K. Komagata: J. Gen. Appl. Micobiol., 7, 282 (1961).

(20) H. Iizuka and K. Komagata: J. Agri. Chem. Soc. Japan., 34, 27 (1960).

(21) H. Iizuka and A. NaIto: J. Gen. Appl. Microbiol., 6, 169 (1960). 